\title{
Branding Thailand: Correcting the negative image of sex tourism
}

Received (in revised form): 30th October, 2006

\section{Krittinee Nuttavuthisit}

is a full-time faculty member of Sasin Graduate Institute of Business Administration of Chulalongkorn University. She teaches courses in Marketing, Consumer Behavior and Qualitative Research. She has also published papers in several international journals including the Journal of Consumer Research, Journal of Consumer Psychology, Journal of Retailing and Journal of Contemporary Ethnography.

\begin{abstract}
As a small emerging country, Thailand has recognised the need to enhance the nation's branding in order to compete in the competitive global marketplace. The Branding Thailand project was initiated by the Thai Government to find out how people worldwide view the nation's strengths and weaknesses. One of the most important issues placing Thailand at a significant disadvantage is the image of sex tourism. This paper illustrates the current situation and analyses the root causes of sex exploitation and perceptual problems. Place branding strategies are proposed to correct the present negative image by placing emphasis on positive characteristics in order to suppress negative perceptions. These strategies include the development of brand positioning through promotional campaigns that use positive features, such as natural beauty and local hospitality, and communication tools such as slogans, themes, visual symbols and events.

Place Branding and Public Diplomacy (2007) 3, 21-30. doi:10.1057/palgrave.pb.6000045
\end{abstract}

Keywords: Branding Thailand, sex tourism, prostitution, negative image, communication tools, brand personality

\section{INTRODUCTION}

Thailand has been competing in the global marketplace based on low cost labour and natural resources and these comparative advantages have made Thailand a regional production hub for various industries, such as the automotive, clothing and electronics industries. The country's position

Correspondence:

Krittinee Nuttavuthisit,

Sasin Graduate Institute of Business

Administration of Chulalongkorn

University,

Phyathai,

Bangkok 10330,

Thailand.

Tel: +6622184080

Fax: +66 22161310

e-mail: krittinee.nuttavuthisit@

sasin.edu as an OEM (Original Equipment

Manufacturer), however, cannot be sustained, particularly with the entry of China into the WTO and the emergence of lower cost competitors in the region. It is essential that Thailand finds a way to change this situation and pursue a different strategy and new country brand image.
Many projects have recently been developed at a national level, such as 'Bangkok Fashion City', 'Kitchen to the World', 'Health Hub of Asia' and the famous tourism campaign, 'Amazing Thailand'. These initiatives were based on the results of the 'Branding Thailand' study of Thailand's competitive position that explored the perceptions of consumers all over the world towards Thailand, ranging from delight to resentment and tangible to intangible attributes of Thailand's image. While Thailand can benefit a great deal from positive perceptions, such as the hospitality of the Thai people, it also suffers from negative stereotypes, such as sex tourism. 
This paper aims to explore the challenge of Thailand being associated with the problems of sex and prostitution. The Branding Thailand Project empirical study provided insight into the way in which people, both visitors and non-visitors, perceive Thailand, particularly in the area of tourism. Analyses of the current situation and the root causes of this problem are illustrated, followed by the place branding strategies that are proposed to correct this negative image.

\section{BRANDING THAILAND PROJECT}

The Branding Thailand Project was initiated by the Government of Thailand in 2001 with the support of two important business schools, Sasin Graduate Institute of Business Administration at Chulalongkorn University (Thailand) and the Kellogg School of Management at Northwestern University (USA). The purpose of the project was to determine Thailand's brand equity from the perceptions of prospective consumers towards Thailand and its major industries: namely cuisine, fashion and tourism. A better understanding of Thailand's brand positioning would contribute to the development of a more comprehensive national strategy in the global marketplace (Maesincee et al., 2003).

\section{Methodology}

The research was conducted over a period of one year, from April 2002 to May 2003, on a diverse consumer base of people who may or may not be users of Thai products or services. Focus groups and in-depth interviews in the United States and 1,000 online surveys of consumers in 30 countries yielded a 12 per cent response rate and the Branding Thailand research provided a detailed qualitative and quantitative account of consumer perspectives of the essential characteristics of Thailand.

Focus groups and in-depth interviews were conducted with 30 consumers in the United States, one of the major markets that interact with Thailand through tourism, trade and investment. A broad sampling of consumers was used in order to capture as many different experiences and perceptions as possible and interviews ranged in length from $30 \mathrm{~min}$ to $1 \mathrm{~h}$. Overall, the interview discussions began with a series of 'grand tour' questions (McCracken, 1988) concerning the participants' backgrounds and the circumstances that resulted in their interaction with Thailand. The purpose of using this initial interview method was to set a foundation for further dialogue about their specific perspectives on Thailand. Subsequent interviews followed in which the participants were asked to describe their views of Thailand, Thai products or Thai services, both in general and in detail (eg specific stories or even fantasies). The studies yield a detailed qualitative account of the perspectives of these consumers. Interpretation of the data was continuously revised during the research process as additional information was collected.

The online survey was divided into two main sections. The first section was designed to explore general decision factors and the countries most frequently connected with particular products or services, without any reference to Thailand. Examples of questions: 'In choosing your preferred holiday destination how important a factor is the following?' and 'What is the first country that comes to mind when thinking about "silk"?' The second section consisted of questions about the way in which Thailand and some of its key products or services are perceived. For example, 'What are the first words that come to mind when thinking of Thailand?' and 'Which three words describe Thai products?' In addition, questions about concept testing were asked in this section, for example "Can Thailand become the "Tourism Capital of Asia"?'

In response to the question about word association with Thailand, the majority of respondents mentioned positive notions, such as 'exotic' and 'friendly people'. There were, however, quite a few comments about negative qualities, such as 'sex/prostitution' and 'poor/ poverty' (see Figure 1). Most of the responses represented mixed perceptions of both positive and negative images of Thailand. Examples of 


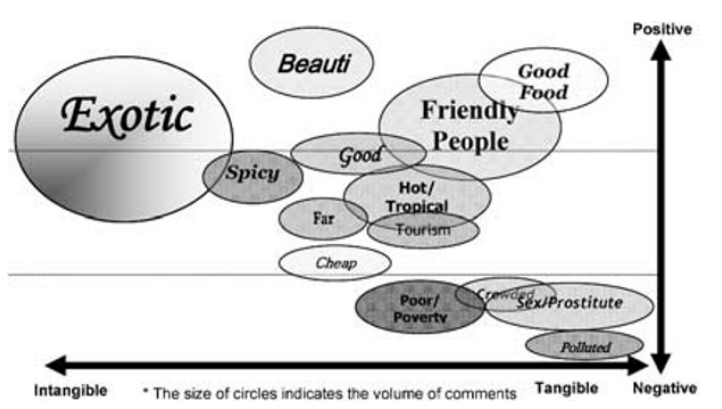

Figure 1: Responses to the question: 'What are the first words that come to mind when thinking of Thailand?'

such reactions, particularly about the problem of prostitution include:

'Sex, local cuisine, dances, forests' (Argentina, Male)

'Steamy, colourful, crowded, poverty, prostitution, beaches' (USA, Female)

'Beaches, beggars, sex' (USA, Male)

'Temples in the forest, prostitution of children'

(France, Female)

'Countryside; well marketed; friendly;

prostitution problems' (USA, Male).

When asked further for suggestions to improve the Thai tourism industry, many respondents, both male and female, strongly called for Thailand to clean up and control its sex trade industry, describing this as a major reason for dislike of the country. Moreover, respondents, especially those who have never been to Thailand, claimed that they have heard and seen many television programmes or magazine articles about Thailand's sex industry, which resulted in bad impressions of Thailand for them. This led to their suggestions that Thailand work on eliminating this sex-related image by communicating a clearer and cleaner image of Thai tourism. Examples of such responses include:

'Control prostitution which gives a biased image of the country which is so beautiful otherwise' (China, Male)

'Get rid of industrial sex' (Belgium, Male)

'Thailand's reputation as a holiday destination has been sullied by the many articles and television reports of Thailand's sex trade, the growing AIDs epidemic and the treatment of orphans, especially girls' (USA, Female).

The findings of the Branding Thailand research help in identifying both the strengths and weaknesses of the country from a market perspective. Focusing on the problem of the negative image associated with sex tourism, particularly among consumers (ie current and future tourists), it is crucial that Thailand develops a clear and effective strategy to address this problem. The following sections elaborate on the issue of Thailand and sex tourism, with analyses of the current situation, causes of the problem and place branding strategies that are proposed to deal with this stereotype.

\section{THAILAND AND SEX TOURISM}

The term 'sex tourism' generally refers to tourists who travel to other countries specifically to purchase the sexual services of local women (and men) (Enloe, 1989). Different forms of the sex trade flourish worldwide, ranging from pornography to erotic phone calls, call girls and hostesses, sexually provocative shows, mail-order brides, street prostitution or illegal brothels. The nature and terms of exchanges between sex tourists and sex workers vary in different places, as does the degree to which each country deals with this business (Davidson and Taylor, 1996). Sex tourism has become a major source of income in some countries, particularly those with poor and underprivileged sectors, to the point that some countries have even tried to promote the business.

Sex tourism is anchored in networks that provide services such as prostitutes, tourist guides, show organisers or massage parlours, and that serve not only foreign tourists but local customers as well (Quintanilla, 1997). Many people are attracted to this business because it is perceived as an easy way to earn money by using one's body, rather than working in more restrictive jobs such as domestic work or physical labour. Despite the notoriety and violation of human rights, the 
sexual exploitation of minors, that is children and adolescents, also exists at various levels.

Thailand undeniably has serious problems regarding the sex trade, as do many other countries. There is, however, a perception that the problem is much worse in Thailand because many people think that the country provides easy access to these types of services. Kusy (1991) claimed that Thailand's sex industry has become a tourist attraction in itself, with red light districts being recommended in several reputable guidebooks. Estimates of the number of prostitutes in Thailand vary widely and are subject to controversial debate. Statistics reported by the International Labor Office (ILO) in 1998 indicated that of a total of 104,262 employees in 7,759 establishments where sexual services could be bought, 64,886 people sold sex services, while 39,376 were support personnel, for example owners or procurers (Lim, 1998). The US Department of State Human Rights Report (2005) estimated that there are 200,000-300,000 sex workers in Thailand.

Previous research has addressed many root causes, such as the economic, social, political, institutional and ideological factors, that have led to the growth of sex tourism in Southeast Asia (Barry, 1979). Poverty appears to be the basic cause of prostitution, although this is not exclusive. Phongpaichit (1982) explained that many sex workers in Thailand were engaged in the business to work off their families' debts and to sustain their family units in a rural economy. Their jobs allow them to provide materials, acquire land, build new houses or buy vehicles (Kabilsingh, 1991). Moreover, the money they earn gives them feelings of independence, opportunity, power and glamour, which they never expected to obtain otherwise (Odzer, 1994).

In addition to the need to escape from poverty, other determining factors, such as an increasing culture of consumption and higher pressure to succeed in a materialistic world, drive girls or women at risk to find ways to earn money to buy new clothes or accessories. The desire to be rich and to gain some social status in the Thai economy not only lures many people into prostitution, but also keeps them there (Ford and Koetsawang, 1991). The living conditions of the financially least-advantaged sectors give rise to marked vulnerability where values are distorted, leading to related problems such as prostitution and poverty (Quintanilla, 1997). Sex tourists in Thailand find themselves with the economic power to look for choices of sexual pleasures in a variety of settings and transactions. Odzer (1994) called these tourists 'neocolonialist kings-for-a-day' who use their affluence to exploit the relative poverty of the unfortunate. The proliferation of multiple forms of the sex trade has been found to occur simultaneously with growth of the entertainment industry, particularly if government policy is to promote the overall recreation sector.

The strong association between Thailand and sex tourism started during the Vietnam War in the 1960s and 1970s, when Thailand and the US military signed a treaty allowing US soldiers to come to Thailand for 'Rest and Recreation' (Truong, 1990; Miller, 1995). The US military presence and the massive scale of tourist development since then are factors that have given rise to increase in the sex trade. The sex industry has been linked to the booming tourism business and sexual labour has become another product of capitalism to earn foreign exchange (Truong, 1990). In Europe there are many promotional campaigns advertising sex tourism in Thailand, for example the 'Thailand Express Sex Tour' referred to Bangkok as 'one big brothel' (Hantrakul, 1988). Such advertising, however, cannot be held solely responsible for damaging Thailand's image and for the spread of prostitution in the country. It has to be recognised that supporting factors that add to this negative image stem from corrupt law enforcement that allows commercial sex services to thrive in the country, even though it is technically illegal in Thailand to sell sexual services. Moreover, people in Thailand avoid talking or commenting openly about this issue since it is a taboo subject in Thai society (Bishop and Robinson, 1998). Accepting the 
situation means also recognising that this jeopardises the image of Thailand as a civilised and respectable nation (Jeffrey, 2002).

The sex trade also brought related problems, such as AIDS. Booranapim and Mainwaring (2002) noted that Thailand was one of the first Asian countries to be affected by the deadly disease, with the first case being diagnosed in 1987. Transmission of AIDS was, at first, mainly via the sex trade and among drug users, and by 1997 there were an estimated 800,000 people in Thailand infected with HIV, the vast majority being commercial sex workers and their clients (UNAIDS, 1997). Thailand has taken a serious approach in dealing with this problem, including a ' 100 per cent condom' programme promoting the use of condoms in brothels, education about the AIDS pandemic and efforts to teach prostitutes to insist on condom use. Despite these attempts, once AIDS in Thailand began to receive media attention there has been a drop in tourist arrivals in Thailand while, at the same time, there has been an increase in the numbers of visitors to neighbouring Asian countries (Chon et al., 1993; Belk et al., 1998).

The issue of sex exploitation must be viewed from a wider perspective. While some studies believe that prostitution is a violation of human rights and an outrage to the dignity of women (Barry, 1991), in many cases prostitution appears as a distinctive form of economic exploitation rather than sexual oppression. Women from poor or underprivileged families may agree to participate in the sex trade in order to gain an economic opportunity to support their households. Liberal feminists believe that prostitution can be regarded as a rational choice given such circumstances. In the network of sex tourism it is not only sex tourists who derive benefits, but the others in the network (eg prostitutes, local entrepreneurs and leisure companies) also gain economic benefits from foreign exchange earnings. Arguably, sometimes it is not the sex tourists but these stakeholders with an economic interest who try to expand and maintain ongoing sex tourism.

Whether the reality of sex tourism is a form of economic exploitation or a violation of human rights, the country image of Thailand has been jeopardised by this association of Thailand with sex tourism over a long period. This negative image has been widely and wildly publicised through the impact of global media. The Longman Dictionary of English Language and Culture (1993) once referred to Bangkok as 'The capital of Thailand, a place often associated with prostitution'. The Economist, volume 369 (December 2003), stated 'throw a stone in Bangkok, and the chances are you will hit a gambler or a brothel goer'. Popular culture presents the reputation of Thailand as a haven for sexual adventures, as shown in many movies, songs and music videos. For example, the popular singer Christina Aguilera appears in her music video 'Dirty', dancing in pools of muddy water in a boxing ring with a pair of posters written in Thai shown in the background that refer to the country's sex industry. Another example is the Hollywood movie, 'Bridget Jones' Diary: The Edge of Reason', which has a scene that shows how a hotel guest can easily get in-room prostitute service in Thailand.

To correct this negative image, Thailand needs to work on both real improvement (eg government policy) and image improvement (eg place branding strategy). Fortunately, Thailand also possesses many positive features and images, such as beautiful natural scenery, a rich history and a unique culture. The results of the Branding Thailand research demonstrated that there is an opportunity to build and develop strategies to manage the perceived images of Thailand. Indeed, Freire (2005) proposed that since stereotypes are dynamic and evolving these can be changed into a positive image with appropriate place branding strategy.

\section{PLACE BRANDING STRATEGY}

The Government of Thailand recognises that the country is undergoing a serious problem by being negatively associated with the sex industry. To correct this situation, the government needs to urge the development of a branding strategy to correct the present image of Thailand and reshape perceptions, while 
simultaneously taking direct action against sex tourism via government policy.

So far, typical government positions have been to repress or prohibit prostitution, particularly child exploitation and human trafficking. NGOs and other organisations, both local and international, have been working proactively on addressing the issue and urging the Thai authorities to regulate penalisation of the exploiters of sex workers. These policies, however, have been considered insufficient in view of the rapid growth of the sex trade. Another policy is to increase prevention programmes and provide more choices of lifestyle for people who choose to engage in prostitution. One example of this in Thailand is a counselling programme in education and employment aimed specifically at young girls at risk of being recruited into the sex trade.

Most action taken to assist those who are the objects of trade in sex and to penalise procurers has been unsuccessful. In order to successfully tackle the sex trade and promote positive change, all stakeholders involved in the tourism business need to be more responsible and active in the elimination of the trade in sex that has emerged so rapidly over the past few decades. The commitment of society as a whole is necessary as this issue involves not only much prejudice but also requires more knowledge and information through research on the magnitude of the problem in order to understand the true situation.

Kotler et al. (2002) proposed that place image is a result of the mind trying to process and frame the beliefs, ideas and impressions that people connect with a place and that when no positive data is available negative processing results in the association of information. Thus, in the case of a negative stereotype, such as Thailand and sex tourism, certain positive factors need to be accentuated while simultaneously trying to change the realities that give rise to the negative place image. Real improvements, such as the development of appropriate government policy, must be highlighted in conjunction with an image improvement concept. As Johnston (2006) stressed, it is crucial to emphasise the positive features when trying to correct a negative perception.

\section{The core elements of place branding}

Thailand's positive qualities can be enhanced at multiple levels, ranging from the physical environment to public services, entertainment and recreation attractions and the nature of the Thai people. These collective components provide opportunities for Thailand to compete in the global marketplace. Thailand has the advantages of a variety of diverse natural attractions, consisting of mountains, forests, waterfalls, rivers and beaches, combined with a rich history and culture. Traditional customs offer occasions to celebrate and enjoy festive activities and Thailand is also one of the best places to shop, where visitors can find a wide selection of products and services at reasonable prices.

The present underdeveloped infrastructure may, however, undermine Thailand's attractions by causing problems such as traffic jams, pollution and poor waste management. Although the Branding Thailand research found that consumers (ie tourists) place less emphasis on such factors compared to recreational and entertainment attractions, infrastructure must be improved and public services (eg protection of people and property, social security and education) must be developed to accommodate expansion of the tourism industry.

Among all the positive features of Thailand, 'people' are always ranked as a leading characteristic that reflects the magnificent hospitality of the country. This factor has a specific impact on consumers as the friendliness of the Thai people creates a positive experience for visitors who then influence their families and friends. Rather than only relying on such positive experiences, appropriate place branding strategy can help by setting the stage to illuminate these qualities. For instance, programmes such as home stay holidays that highlight the warmth of Thai hospitality should be emphasised in the national tourism plan. 
Adventure programmes can also capitalise on the natural beauty of Thailand while not requiring improved infrastructure. Because the impression of hospitality may be formed by contacts with both local residents and 'other tourists', Thailand needs to also manage tourist sites in a way that will mainly attract particular groups of visitors. People do not like to associate with others that they find unacceptable or undesirable and sex tourists create a negative impact on the country's image. Therefore, Thailand has to evoke a clear and concrete brand positioning as opposing the business of sexual exploitation.

\section{Place characteristics and brand personality}

In addition to the core elements of a place, its positive characteristics need to be promoted simultaneously since consumers make decisions based on not only functional quality but also on the representational and emotional quality of a place. The concept of brand personality is strongly emphasised in contemporary business because it denotes symbolic meanings beyond practical attributes. This can be defined as the set of human characteristics associated with a given brand (Aaker, 1996). Brand personality is strongly associated with a specific place since consumers often perceive the place image based on characteristics of the place and people who live there (Kotler et al., 2002).

Realising that people are an important factor in determining place image and positioning, Nuttavuthisit (2005) has developed a typology of Thai-ness that defines the four major characteristics of Thailand branding. Based on consumer perceptions of Thailand, these are 'Fun', 'Fulfilling', 'Friendly' and 'Flexible'. These brand personalities illustrate a mix of the characteristics of the Thai lifestyle and places in Thailand. The notion of 'Fun' denotes a vibrant and entertaining experience that consumers perceive in the Thai lifestyle, in a people who enjoy a dynamic lifestyle that includes going out, celebrating and having fun. 'Fulfilling' is perceived as a sense of escape from reality or peace of mind evoked in the relaxed lifestyle and tranquil places of Thailand. 'Friendly' is the expression most used by consumers when referring to Thailand as a comfortable environment and, finally, feelings of 'Flexibility' were expressed when consumers noted the easygoing relationships among the diversity of people, places and situations in Thailand.

This juxtaposition of 'fun', 'fulfilling', 'friendly' and 'flexible' characteristics appears in a 'fusion' form rather than as rigid beliefs, opinions or attitudes, because of the multilayered meanings of Thai individuality, history, society and culture. This analysis of place characteristics and brand personality illustrates the underlying structure of consumers' holistic perspectives and promotes a greater insight into Thailand's brand image.

\section{Place branding communication tools}

To implement an effective image improvement for Thailand, the positive elements and characteristics of Thailand must be communicated to both tourists and local residents as the image of a place is influenced by perceived values delivered to customers. Tourism campaigns normally carry a slogan or tagline to unify and underline the values and identities of the place being promoted. For example, South Australia has the slogan 'Relax, Indulge, Discover, Enjoy' and the Maldives has the slogan 'The Sunny Side of Life'. The Thailand tourism campaign has been quite successful in terms of public awareness using the concept 'Amazing Thailand', particularly since many tourists enjoy the idea of experimenting with something new, exotic or different from their home environment or daily life. Yet, in choosing words to represent and position the country's image, not only must positive meanings be considered but also any possibility of implying negative connotations.

Although Branding Thailand study findings show that the word 'exotic' is most frequently associated with the image of Thailand and conveys the amazing quality of the country, this word also needs to be avoided as it can convey 
a sexual attribute and trigger an impression of sex tourism. Hall (1992) noted that part of the Thailand's appeal to sex tourists is due to its image of the 'exotic orient' with the low cost of prostitution. Terms such as warmth and intimacy can convey friendliness, however, some people associate these as the characteristics of Thai prostitutes that distinguish them from sex workers in other countries, who are perceived as cold and commercialised (Davidson and Taylor, 1996). Moreover, sometimes the flexibility that characterises the Thai people appears in a form that leads to a negative perception. In a study of British sex tourists in Thailand (ibid), some respondents referred to the supposedly subservient and accommodating nature of Thai women as being genetically and culturally predisposed towards subordination and self-denial.

Another place branding communication tool is the use of visual symbols. Some places utilise landmark sites that can be easily imprinted in people's minds and associated with specific places. For example, the Opera House with Sydney, the Great Wall of China with Beijing and the Taj Mahal with Agra. A successful visual symbol needs to symbolise and reinforce an image of a specific place and also must be consistent with the slogan or theme of that place. Hong Kong's latest brand development selected the slogan 'Asia's World City' and chose to use the image of a dragon depicted in a smooth and fluid shape. This logo also incorporates the letters HK and the country's name written in Chinese calligraphy. The idea is to convey a sense of movement, speed and change and reflect the characteristics of the country (Yu, 2003). Nevertheless, this place branding campaign has suffered from a problem with low recognition and understanding and requires further development to communicate the correct image to both local residents and international tourists and investors.

Kotler et al. (2002) proposed that one way of handling a negative image of a place is to use the 'denying visual' to overwhelm the target audience with positive images. This strategy comes with risks. Bangkok has always portrayed itself using a picture of the Grand Palace depicted as a picturesque and serene image, whereas in reality the Grand Palace is situated in the middle of the city amid highly congested traffic. This 'denying visual' results in frustration among visitors with high expectations as they feel they are being tricked by the place branding campaign. Porritt (2006) suggested that sophisticated tourists become very uncomfortable about any mismatch between an image projected via marketing tools and reality.

In addition to the use of landmarks as visual symbols, Thailand has also been portrayed by images of Thai people (eg the picture of beautiful flight attendants used by Thai Airways International) designed to convey the positioning of Thai hospitality. Using pictures of Thai women must be well thought out, particularly in view of the negative stigma of the sex trade in Thailand. In a research study using a focus group of foreign visitors that was conducted by the Tourism Authority of Thailand, one participant referred to a series of highway billboards of an airline that portrayed a series of young girls smiling. He mentioned that it somewhat elicited an association of the country with sex tourism.

Marketing events are an interactive tool that can epitomise and communicate a desired image and place brand positioning to participative audiences. Such events can be combined to create strong awareness or distributed to gradually influence an audience over a period of time and even be held outside the country in order to reach target audiences. For instance, the Tourism Authority of Thailand is presently promoting the concept of health-tourism at many overseas exhibitions and seminars. With demonstrations by skilled Thai masseurs and information on the history of traditional Thai herbal treatments, the organisation aims to generate a better understanding and correct the negative association between the word 'massage' and the common perception of massage parlours and brothels.

Place branding events organised in the country can also draw tourists to appreciate the 
real experience. Examples of successful events are the Mardi Gras in New Orleans, the Dragon Boat Festival in China and bullfights in Spain. In Thailand there are many famous annual events, mainly associated with traditional customs and culture, such as the Thai New Year celebration in April and an annual gathering by the Mekong River at the end of Buddhist Lent to observe the phenomenon of mysterious fireballs. Thailand can promote the positive experiences derived from being a part of these events, particularly through the testimonials of tourists. Most importantly this, however, needs to reinforce the core elements and characteristics of Thailand's image. An interesting example from the Branding Thailand research is that one participant made an observation about the 'fun' attribute of Thailand demonstrated in the many festive events

'I think "Fun" is part of the culture. Thai people ... they like to go out, celebrate and have fun. It's more open in Thailand. At the same time you have these fun places that cater to that. I think people [non-Thais] can almost "osmosis" that feeling, you know. You just soak it in. They can sense that. They can realize that.'

\section{CONCLUSION}

The Branding Thailand study demonstrated the areas in which Thailand can capture a competitive positioning in the global marketplace, such as the fine quality of Thai cuisine or the Amazing Thailand tourist experience. At the same time, the results showed a significant area of negative image associated with Thailand that can jeopardise major businesses, that is the problem of sex tourism. Thailand is making efforts to try and correct this problem through a real improvement programme, including the development of government policy to correct the deep-rooted causes of the sex trade problem (eg lack of economic opportunity and corrupt law enforcement). At the same time, an image improvement programme is needed realising that place image is the sum of the beliefs, ideas and impressions that people have of a place (Kotler et al., 2002).
Anholt (2006) proposed that a country with a poor place brand image often finds that the world media will react with cynicism or indifference to its positive qualities, while the negative associations are fascinated and given prominence. Hence, it is essential that Thailand place emphasis on place branding strategies to support the image improvement programme.

The implementation of place branding strategies must be encouraged at all levels including not only organisations involved with international tourists but also the local population, because community self-perception is highly important in building long-term, sustainable place equity. During the process of reshaping a country's image, nation branding is crucially about building and reinforcing a collective identity in a holistic manner. Elements of places and people must come together to evoke a dynamic impact in the international marketplace. Most importantly, critical attention to and follow-up of the situation is essential in order to tackle the serious problem of the sex trade. Cooperation among stakeholders, such as local residents, government sectors and business organisations, can help fight against the core root causes of sex exploitation, correct the negative image of sex tourism and promote positive positioning of the nation.

\section{References}

Aaker, D. A. (1996) ‘Building Strong Brands', Free Press Business, London, UK.

Anholt, S. (2006) 'Editorial: Is place branding a capitalist tool?' Place Branding, Vol. 2, No. 1, pp. 1-4.

Barry, K. (1979) 'Female Sexual Slavery', Prentice Hall, Englewood Cliffs, New Jersey.

Barry, K. (1991) 'The Penn State Report on Sexual Exploitation, Violence and Prostitution', UNESCO: Coalition Against Trafficking in Women.

Belk, R. W., Ostergaard, P. and Groves, R. (1998) 'Sexual consumption in the time of AIDS: A study of prostitute patronage in Thailand', Journal of Public Policy and Marketing, Vol. 17, No. 2, pp. 197-214.

Bishop, R. and Robinson, S. (1998) 'Night Market', Routledge, New York, NY.

Booranapim, Y. and Mainwaring, L. (2002) 'Risk and reward in the Thai sex industry', International Journal of Social Economics, Vol. 34, No. 3, pp. 766-779.

Chon, K., Singh, A. and Mikula, J. R. (1993) 'Thailand's tourism and hotel industry', Cornell H.R.A.Quarterly, June, Vol.34, No. 3, pp. 43-49. 
Davidson, J. O. and Taylor, J. S. (1996) 'Child Prostitution and Sex Tourism: Thailand', ECPAT: A series for the world congress against the commercial sexual exploitation of children.

Enloe, C. (1989) 'Bananas, Beaches \& Bases', Pandora, London, UK.

Ford, N. and Koetsawang, S. (1991) 'The socio-cultural context of the transmission of HIV in Thailand', Social Science and Medicine, Vol. 33, No. 4, pp. 405-414.

Freire, J. (2005) 'Geo-branding: Are we talking nonsense?: A theoretical reflection on brands applied to places', Place Branding, Vol. 1, No. 4, pp. 347-362.

Hall, C. M. (1992) 'Sex tourism in Southeast Asia', in Harrison, D. (ed.)'Tourism and the Less Developed Countries', Belhaven Press, London, UK, pp. 64-74.

Hantrakul, S. (1988) 'Prostitution in Thailand', in Chandler, G., Sullivan, N. and Branson, J. (eds).'Development and Displacement of Women in South East Asia', Center of Southeast Asian Studies, Monash University, Victoria, Australia, pp. 115-136.

Jeffrey, L. A. (2002) 'Sex and Borders: Gender, National Identity, and Prostitution Policy in Thailand', UBC Press, Vancouver, Canada.

Johnston, Y. (2006) 'Opinion pieces: How has place branding developed during the year that Place Branding has been in publication?' Place Branding, Vol. 2, No. 1, pp. 6-17.

Kabilsingh, C. (1991) 'Thai Women in Buddhism', Parallax Press, Berkeley, CA.

Kotler, P., Hamlin, M. A., Rein, I. and Haider, D. H. (2002) 'Marketing Asian Places: Attracting Investment, Industry, and Tourism to Cities, States, and Nations', John Wiley \& Sons (Asia) Pte Ltd., Singapore.

Kusy, F. (1991) 'Thailand', Cadogan, London, UK.

Lim, L. L. (1998) 'The Sex Sector: The Economic and Social Bases of Prostitution in Southeast Asia', International Labour Organization, Geneva, Switzerland.
Maesincee, S., Nuttavuthisit, K., Ayawongs, A. and Phasukvanich, N. (2003) 'Branding Thailand: Building a favorable country image for Thai products and services', Sasin Journal of Management, Vol. 9, No. 1, pp. 21-26.

McCracken, G. (1988) 'The Long Interview', Sage Publications Ltd., Newbury Park, CA.

Miller, J. (1995) 'Sex tourism in Southeast Asia', in Thio, A. and Calhoun, T. (eds)'Deviant Behavior', Harper Collins, New York, NY, pp. 278-283.

Nuttavuthisit, K. (2005) 'The Holistic Perspective of Thailand Brand Meaning, Proceeding: The 9th International Conference on Global Business and Economic Development, May 2005.

Odzer, C. (1994) 'Patpong Sisters: An American Woman's View of the Bangkok Sex World', Arcade, New York, NY.

Phongpaichit, P. (1982) 'From Peasant Girls to Bangkok Masseuses: Women, Work, and Development', International Labour Organization, Geneva, Switzerland.

Porritt, J. (2006) 'Opinion pieces: How has place branding developed during the year that Place Branding has been in publication?' Place Branding, Vol. 2, No. 1, pp. 6-17.

Quintanilla,T. (1997) 'Globalization of sex trade', The Big Issues: Reports by commitment. Retrieved 16 August, 2006, from http://www.socialwatch.org/en/informesTematicos /40. html.

Truong, T. (1990) 'Sex, Money and Morality', Zed Books Ltd., London, UK.

UNAIDS (1997) 'Global Summary of the HIV/AIDS Epidemic', United Nations, New York, NY.

US Department of State Human Rights Report (2005) Retrieved 23 August, 2006, from http://www. humantrafficking.org/countries/thailand.

Yu, J. (2003) 'Asia's World City: Hong Kong's New Identity', Center for Asian Business Cases, The University of Hong Kong, Hong Kong. 